\title{
Don't worry, I've got it covered
}

\author{
Joshua B. Goldberg, MD, Steven Lansman, MD, PhD, and David Spielvogel, MD
}

\author{
From the Division of Cardiothoracic Surgery, Department of Surgery, Westchester Medical Center, New York \\ Medical College, Valhalla, NY. \\ Disclosures: Authors have nothing to disclose with regard to commercial support. \\ Received for publication May 15, 2017; accepted for publication May 18, 2017; available ahead of print June 20, \\ 2017. \\ Address for reprints: David Spielvogel, MD, Cardiothoracic Surgery, 100 Woods Rd, Macy Pavilion 114W, \\ Valhalla, NY 10595 (E-mail: David.Spielvogel@wmchealth.org). \\ J Thorac Cardiovasc Surg 2017;154:1497 \\ 0022-5223/\$36.00 \\ Copyright (C) 2017 by The American Association for Thoracic Surgery \\ http://dx.doi.org/10.1016/j.jtcvs.2017.05.057
}

Piffaretti and colleagues ${ }^{1}$ deserve praise for compiling an innovative series that may extend the use of simple endografts for the treatment of a subset of thoracoabdominal aneurysms. Their article in this issue of the Journal describes the intentional coverage and occlusion of the celiac artery to gain landing zone length in the treatment of type I and V thoracoabdominal aneurysms. Among 17 patients studied, a mean gain of $18 \mathrm{~mm}$ in seal zone length was achieved. Except for a $6 \%(1 / 17)$ permanent spinal cord injury (SCI) rate, their outcomes were promising, with no type I or type II endoleaks, no visceral ischemia requiring intervention, and no in-hospital deaths. After a mean follow-up of 36 months, the cumulative freedom from aorta-related mortality was $94 \%$. Importantly, Piffaretti and colleagues ${ }^{1}$ outlined their rigorous selection criteria and intraoperative and postoperative management strategies.

Two major concerns with this technique deserve mention. The first is the increased risk of visceral ischemia. Although no cases of visceral ischemia required operative intervention in this series, other studies have reported mesenteric ischemia rates ranging from $6 \%$ to $20 \%$ with intentional celiac artery coverage. ${ }^{2-4}$ Undoubtedly, the careful preoperative assessment and perioperative management regimen used by Piffaretti and colleagues ${ }^{1}$ contributed to their promising outcomes; this is a small series, however, and, given the devastating mortality and morbidity ensuing from mesenteric ischemia, 1 or 2 such complications in the next group of patients or in the hands of other teams might color the appeal of this technique.

Second, extending thoracic endovascular aortic repair coverage to the visceral segment increases the risk of SCI by 2 mechanisms. The first is that increasing the number of occluded intercostal segments increases the risk of SCI as a result of limiting inflow to the spinal collateral network. ${ }^{5}$ For the same reason, the risk of SCI is compounded if the extent of coverage includes the subclavian artery, reinforcing the need to maintain subclavian perfusion. The second mechanism, as demonstrated clearly in animal studies, is that the risk of SCI is significantly increased

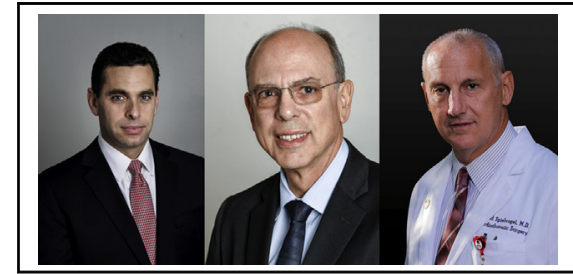

Left to right. Joshua B. Goldberg, MD, Steven Lansman, MD, PhD, and David Spielvogel, MD.

\section{Central Message}

Intentional occlusion and coverage of the celiac artery during endovascular aneurysm repair increases the risk of visceral and spinal ischemia.

See Article page 1487.

by visceral ischemia. ${ }^{6,7}$ Attributed to an inflammatory effect on the spinal cord vasculature, any visceral malperfusion, even if "minor," may adversely affect spinal cord perfusion, and even short-term visceral ischemia has been shown to affect the spinal cord permanently.

Teams seeking to adopt this technique should adhere strictly to Piffaretti and colleagues' rigorous selection criteria and management strategies to mitigate risk. In addition, surgeons should remember that in the modern era open, thoracoabdominal aneurysm repair has low mortality and complication rates, even in patients at high risk. ${ }^{8}$

\section{References}

1. Piffaretti G, Fontana F, Franchin M, Bacuzzi A, Dorigo W, Castelli P, Tozzi M. Total endovascular treatment for extent 1 and 5 thoracoabdominal aortic aneurysms. J Thorac Cardiovasc Surg. 2017;154:1487-96.e1.

2. Rose MK, Pearce BJ, Matthews TC, Patterson MA, Passman MA, Jordan WD Outcomes after celiac artery coverage during thoracic endovascular aortic aneurysm repair. J Vasc Surg. 2015;62:36-42.

3. Mehta M, Darling RC III, Taggert JB, Roddy SP, Sternbach Y, Ozsvath KJ, et al Outcomes of planned celiac artery coverage during TEVAR. J Vasc Surg. 2010;52: 1153-8.

4. Hyhlik-Dürr A, Geisbüsch P, von Tengg-Kobligk H, Klemm K, Böckler D. Intentional overstenting of the celiac trunk during thoracic endovascular aortic repair: preoperative role of multislice CT angiography. J Endovasc Ther. 2009;16:48-54.

5. Zoli S, Etz CD, Roder F, Brenner RM, Bodian CA, Kleinman G, et al. Experimental two-stage simulated repair of extensive thoracoabdominal aneurysms reduces paraplegia risk. Ann Thorac Surg. 2010;90:722-9.

6. Elbers PW, de Haan P, Vanicky I, Legemate D, Dzoljic M. Effect of temporary visceral ischemia on spinal cord ischemic damage in the rabbit. Ann Thorac Surg. 2006;81:910-7.

7. Morrissey NJ, Kantonen I, Liu H, Sidiqui M, Marin ML, Hollier LH. Effect of mesenteric ischemia/reperfusion on spinal cord injury following transient aortic occlusion in rabbits. J Endovasc Ther. 2002;9(Suppl 2):II44-50.

8. Coselli JS, LeMaire SA, Preventza O, de la Cruz KI, Cooley DA, Price MD, et al Outcomes of 3309 thoracoabdominal aortic aneurysm repairs. J Thorac Cardiovasc Surg. 2016;151:1323-37. 